\title{
Kent Merkezlerinde Ticaret Birimlerin Mekânsal Örüntüsü Üzerine Bir Değerlendirme: Kastamonu Örneği
}

\author{
Öznur IŞINKARALAR ${ }^{1 *}$ (D) Çiğdem VAROL ${ }^{2 \text { (D }}$ \\ ORCID 1: 0000-0001-9774-5137 \\ ORCID 2: 0000-0002-2432-5745 \\ ${ }^{1}$ Kastamonu Üniversitesi, Mühendislik ve Mimarlık Fakültesi, Şehir ve Bölge Planlama Bölümü, 37100, \\ Kastamonu, Türkiye. \\ ${ }^{2}$ Gazi Üniversitesi, Mimarlık Fakültesi, Şehir ve Bölge Planlama Bölümü, 06570, Ankara, Türkiye. \\ *e-mail: obulan@kastamonu.edu.tr
}

Öz

Kentsel alanlarda yer alan işlevler, gelişim süreçleri boyunca farklı perspektiflerden sıklıkla araştırılmış ve yer seçimlerini etkileyen faktörler analiz edilerek irdelenmiştir. Mekânsal yer seçimi dinamiklerini ortaya koymakta öncelikle hiyerarşik bir mekansal düzeni tanımlayan merkezi yerler kuramı ile etki düzeyinin arttırılmasında nüfus ve erişebilirlik bileşenleri gündeme gelmiş ve işlevlerin mekansal örüntü üzerindeki konumları önem kazanmıştır. Bu bağlamda çalışmanın amacı, ticari yapılar ile erişilebilirlik arasındaki ilişkinin kent makroformu üzerinden ortaya konulması ve ticari işlevlerin kademeli yapısının merkezi yerler kuramı çerçevesinde irdelenmesidir. Çalışma Kastamonu kenti Merkez ilç̧e sınırlarında gerçekleştirilmiştir. Ticaret türleri yapılan sınıflandırmaya göre CBS kullanılarak sayısallaştırılmış, hizmet yoğunlukları düşük, orta ve yüksek olarak sınıflandırılarak analiz edilmiştir. Araştırma sonucunda bazı mahallelerde sıkça talep edilen hizmetlerin bile yer almadığı, buna karşın bazı mahallelerin merkezi noktalarında üst kademe hizmetlerin yer aldığı tespit edilmiştir. Araştırma sonucunda kent ölçeğinin tüketiciler için kabul edilebilir mesafeler açısından önemli olduğu ortaya konmuştur.

Anahtar Kelimeler: Ticaret, merkezi iş alanı, merkezi yerler kuramı, yer seçimi, Kastamonu

\section{An Evaluation on the Spatial Pattern of Commercial Units in Urban Centers: The Case of Kastamonu}

\begin{abstract}
Functions in urban areas have been frequently investigated from different perspectives throughout the development process, and factors affecting location choices have been analyzed. In revealing the dynamics of spatial location selection, population and accessibility components came to the fore in increasing the level of influence with the central places theory, which defines a hierarchical spatial order, and the positions of the functions on the spatial pattern have gained importance. In this context, the aim of the study is to reveal the relationship between commercial structures and accessibility in terms of urban macroform and to examine the gradual structure of commercial functions within the framework of central places theory. and service intensities were analyzed by classifying them as low, medium and high. As a result of the research, it has been determined that even the services that are frequently requested are not included in some neighborhoods, while there are high-level services in the central points of some neighborhoods. As a result of the research, it has been revealed that the scale of the city is important in terms of acceptable distances for consumers.
\end{abstract}

Keywords: Commerce, central business district, central place theory, site selection, Kastamonu

Citation/Atıf: Işınkaralar, Ö. ve Varol, Ç. (2021). Kent merkezlerinde ticaret birimlerin mekânsal örüntüsü üzerine bir değerlendirme: Kastamonu örneği. Journal of Architectural Sciences and Applications, 6 (2), 396-403.

DOI: https://doi.org/10.30785/mbud.927529 


\section{Giriş}

Mekânsal biçimlenme süreçleri ve bu süreçlere mekânsal planlamanın müdahale araç ve yöntemleri planlama tarihi boyunca tartışılan en temel konulardan biridir. Mekânın ele alınışı özellikle 1980'li yıllardan bu yana yeni planlama yaklaşım ve yöntemlerini içermeye başlamıştır. Dünyada nüfusun artmasıyla birlikte kent formları değişmiş, mekâna yansıyan kentsel büyüme yer seçim davranışlarının araştırılmasını gerektirmiştir (Sat, Üçer, Varol ve Yenigül, 2017; Önaç ve Biriş̧̧i, 2019; Öztürk ve Işınkaralar, 2019).

Günümüz kentlerinde bu süreçler, yeni liberal siyasaların güç kazandığı bir düzende, sanayi, ulaşım ve haberleşme sektörlerinde meydana gelen teknolojik ilerlemelerin (Karaçocuk, Şevik ve Işınkaralar, 2021; Işınkaralar ve Erdem, 2021; Savaş, Şevik ve Işınkaralar, 2021; Sevik, Işınkaralar ve Işınkaralar, 2018) hayatımızın vazgeçilmez unsurları olmasının etkisiyle daha karmaşık ilişkilere bağlı bir şekilde gelişmektedir. Güncel kentsel çalışmalar, kentler ve bölgelerin ekonomik, sosyal ve kültürel işleyişini ve performansını açıklarken karmaşık ilişkilere dayanan ağ yapılarının önemine vurgu yapmaktadır (Öztürk, Işınkaralar ve Yılmaz, 2021; Öztürk, Işınkaralar, Yılmaz ve Çılgınoğlu, 2021; Öztürk, Işınkaralar Yılmaz ve Ciçek, 2021). Kentlerin belirsiz ve karmaşık yapıda olması nedeniyle kentsel değişim ve dönüşümlerde ortaya çıkış, bitiş veya çözüm tanımlanması oldukça zordur (Iossifova, Doll ve Gasparatos, 2018).

Küresel düzlemde her kent, işlevsel olarak birbirine bağıı kentler sisteminin bir parçasıdır. Kent içerisinde ise spekülatif yapılaşma, geleneksel merkez dışında yeni merkezlerin oluşmasıyla ortaya çıkan çok merkezlilik (Sat, 2018) ve dengeli olarak dağılmış olmayan bir nüfus yapısı söz konusu olabildiğinden (Mutlu ve Varol, 2017), ilişkileri farklı ölçeklerde anlamak ve planlamak zamanla zorlaşmaktadır. Özellikle dünya kentlerinde dış küresel bağlantılar oldukça güçlü olup üretim ve tüketim ilişkileri tahmin edilemeyecek kadar karmaşıktır (Alderson ve Beckfıeld, 2004; Taylor, 2004; Wall ve Van Der Knaap, 2011).

Güncel tartışmalarda rasyonel/determinist planlama anlayışı, sistemlerin kaotik süreçleri nedeniyle eleştirilmektedir. Ancak günlük alışveriş gibi pek çok sosyo-ekonomik sürecin hala yerel olduğu kabul edilmekte olup perakende coğrafyası 1900'lerin başından beri pek çok disiplinin ilgi odağı olmayı sürdürmektedir (Büyükcivelek, 2014). Bu nedenle, alt mekânsal ölçeklerdeki kent merkezlerinin araştırılmasına (Burger, Meijers ve Oort, 2014) ve karmaşık sistem içerisindeki her bir bileşenin değerlendirilmesine duyulan intiyaç artmaktadır (Naryaprağı ve Polat, 2020).

Araştırmanın konusunu oluşturan kent merkezleri, ağsal ilişkilerin kent içerisinde en güçlü olduğu ve mekânsal örüntüsünde işlevlerin çeşitliliği açısından kentin en zengin olduğu alanlardır. Perakende işlevi nedeniyle kent merkezleri, kentlerin dönüşüm ve uyum süreçlerinden büyük ölçüde etkilenmektedir (Büyükcivelek, 2009). Kent merkezlerinin yaşayabilmesi ve alışveriş mekânlarının dirençliliği, şehrin sürdürülebilirliği açısından oldukça önemlidir (Özüduru, Varol ve Ercoşkun, 2014).

Birçok çalışma perakende ticareti yoğunlaşmasının en yüksek olduğu yerler olması nedeniyle, kent merkezlerinin en önemli işlevi olarak belirtmektedir (Davies, 1967). Ticari kullanımlar, kent planı kararlarında "ticaret" olarak ayrılmış alanlarda yer seçmektedir. Ancak ticaret işlevinin türleri, tüketici talepleri, yatırımcı tercihleri, yerelden küresele sosyo-ekonomik gelişmeler gibi birbiriyle etkileşimde olan/olmayan pek çok dinamiğin sürece katılmasıyla ortaya çıkmaktadır. Son zamanlarda, sanayi devriminin ortaya çıkardığı üretim odaklı kent ekonomileri yerini bilgi toplumuna geçişle birlikte hizmetlere bırakmış (Öztürk, İsmail ve Işınkaralar, 2020), değişen perakende ortamının etkisi ve çok satışlı zincirlerin gelişmesi perakende firmaların konumunun önemini artırmıştır (Mendes ve Themido, 2004). Hizmet sağlayıcı firmalar, hayatta kalabilmek ve karlııı̆ını artırabilmek amacıyla doğru yer seçimi yapmalıdır. Bunun için müşteri taleplerini tahmin ederek en uygun yeri seçerler (Kayacan ve Yirmibeşoğlu, 2017; Beyhan, Eren ve Aktuğ, 2020).

Ticari ilişkilerin ana unsuru olan tüketici talepleri ve bu hizmetlerin sunumunu sağlayanlar arasındaki ilişkilere odaklanan açıklamalar, 20. yüzyılın ikinci yarısına dayanmaktadır (Christaller, 1933; Lösch, 1944). Merkezi yerler kuramı, özellikle Christaller'in yaklaşımı, perakende ve tüketici hizmetlerinin coğrafyasının tanımlayıcı bir kuramsal temeli olarak kabul edilmektedir (Meijers, 2007). Merkezi yerler 
kuramı, sundukları hizmetler açısından yerleşimleri kademeli yapıda olarak ifade eder. Kurama göre tüketiciler tarafından mal veya hizmet almak için en yakın merkezin kullanılması ve böylece ulaşım maliyetlerinin en aza indirilmesi söz konusudur. Bununla birlikte sık tercih edilen hizmetler kentsel alanda dağılma eğilimi gösterirken, yüksek etki alanına sahip olan ve ağsal dışsallıkları daha kuvvetli olan hizmetler, ulaşım bağlantılarına erişebilir noktalarda yığılma eğilimindedir (Burger, Meijers ve Oort, 2014). Araştırmada bu yaklaşımdan hareketle ticaret örüntüleri ile mekânsal yapı ilişkisine odaklanarak perakende ticaret birimlerinin yer seçimlerinde merkeziliğin etkisi ve desantralizasyon süreci sorgulanmaktadır.

\section{Materyal ve Yöntem}

Araştırmanın materyalini Kastamonu kent merkezi sınırlarında yer alan ticari işlevlerin sayısal ölçümleri oluşturmaktadır. Karadeniz bölgesinde yer alan Kastamonu (Şekil 1); Çankırı, Karabük, Bartın, Sinop ve Çorum illeri sınır komşusudur. Kent merkezi Karaçomak Vadisi üzerine kurulmuştur. Kent, Karaçomak Çayı ile ikiye bölünmüş bir morfolojide olup (Erkan ve Yenen, 2009), engebeli bir arazi yapısına sahiptir (Öztürk ve Özdemir, 2013). Kent merkezinin Hepkebirler, Atabeygazi, Yavuzselim, Cebrail, Aktekke, Topçuoğlu ve İsfendiyar Mahalleleri Merkezi iş Alanı (MiA) sınırlarında olup 20 merkez mahallesi bulunmaktadır.

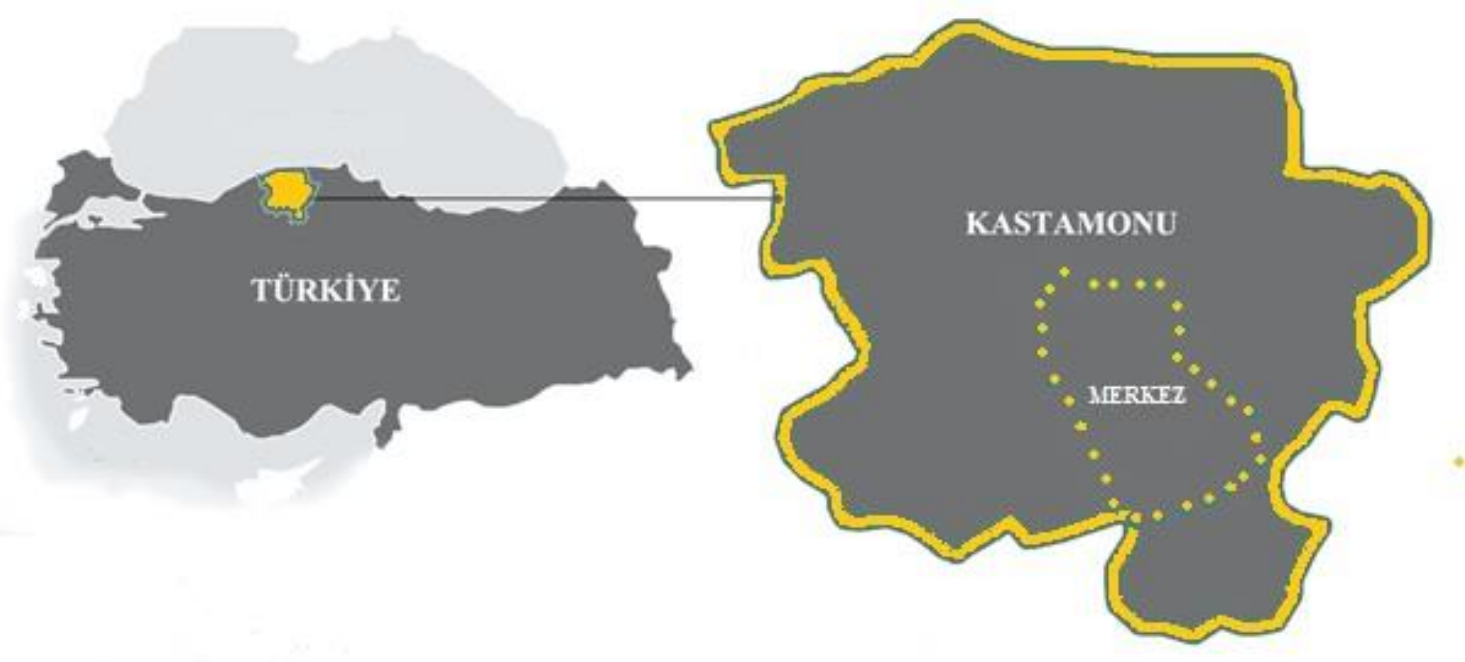

Şekil 1. Çalışma alanının konumu

Araştırma kavramsal çerçeve ve saha araştırması olarak iki düzlemde yürütülmüştür. Kavramsal bölümde ticari birimlerin yer seçim davranışlarını etkileyen kuramsal altyapı, merkezi yerler kuramı bağlamında ele alınmıştır. Kuram ve ona yönelik olarak yapılan tartışmalar çalışmayı yönlendirecek şekilde özetlenmiş ve saha çalışmasını kurgulamak için temel sınıflandırmada kullanılmıştır.

Çizelge 1. Hizmetlerin kategorilere göre dağılımı

\begin{tabular}{|c|c|c|}
\hline Hizmetler & Kategori & Kapsam \\
\hline \multirow{6}{*}{$\begin{array}{l}\text { Sık Kullanılan } \\
\text { Hizmetler }\end{array}$} & Temel alışveriş & $\begin{array}{l}\text { Market, Büfe, Eczane, Gözlükçü, Tuhafiye, Zücaciye, } \\
\text { Çiçekçi, Nakliyat, Nalbur, El sanatları }\end{array}$ \\
\hline & Gıda & $\begin{array}{l}\text { Fırın, Kasap, Manav, Süt ürünleri, Kafe, Restoran, } \\
\text { Şekerleme, Çay bahçesi, Yöresel gıda, Pazar alanı }\end{array}$ \\
\hline & Giyim ve Ayakkabı & Giyim, Ayakkabı, Tekstil \\
\hline & Kişisel bakım ve mücevherat & Mücevher ve saat, Parfümeri, Kuaför ve berber, Antika \\
\hline & Eğlence ve Spor & $\begin{array}{l}\text { Spor malzemeleri, Müzik ve video, Oyun ve oyuncak, } \\
\text { Enstrüman, Lokal, Kıraathane, Düğün salonu }\end{array}$ \\
\hline & Banka ve Ofis & Ofis, Banka ve döviz, Kargo, Veteriner \\
\hline \multirow{6}{*}{$\begin{array}{c}\text { Yüksek } \\
\text { Etki Alanına } \\
\text { Sahip Hizmetler }\end{array}$} & Otomotiv & Araç aksesuarı, Benzinlik, Bisiklet, Otopark \\
\hline & İnşaat-Yapı Malzemeleri & Yapı ve bahçe malzemeleri, Temizlik, İnşaat \\
\hline & Ev Eşyası- Mobilya & Ev aletleri/eşyaları, Mobilya, Boya ve duvar kâğıdı \\
\hline & Teknoloji & Telefon, Kamera ve fotoğraf, Bilgisayar \\
\hline & Eğitim- Konaklama & $\begin{array}{l}\text { Eğitim ve kurs, Kırtasiye, Yurt, Otel-konaklama, } \\
\text { Kitap/gazete }\end{array}$ \\
\hline & Elektrik ve Enerji & Aydınlatma ürünleri, Elektrik ve enerji malzemeleri \\
\hline
\end{tabular}


Söz konusu çerçeveden hareketle çalışmanın materyalini oluşturan Kastamonu kent merkezi sınırlarında yer alan ticari işlevler irdelenmiştir. Araştırma kapsamında yapılan saha çalışmaları ile yapıların zemin katında yer alan ticaret türleri hâlihazır haritalara işlenmiştir. Birimler sıkça talep edilen hizmetler ve tüketicilerin daha uzak mesafelere seyahat etmelerini gerektiren yüksek etki alanına sahip hizmetler olarak kategorilere ayrılmıştır (Çizelge 1).

Tüketicilerin genellikle günlük kullanımına hizmet eden market, fırın, banka vb. kullanımlar sık kullanılan hizmetler, yapı malzemeleri, ev aletleri, elektronik malzemeler vb. kullanımlar ise yüksek etki alanına sahip hizmetler olarak tanımlanmıştır. Hizmetlerin mekânsal örüntüsü CBS yazılımı kullanılarak mahallelere göre analiz edilmiştir. Yapılan analiz sonucu \%25'in altında kalan kullanımlar düşük, \%25$\% 50$ arası orta ve \%50 üstü ise yüksek yoğunluk olarak kabul edilmiştir.

\section{Bulgular ve Tartışma}

Sahadan elde edilen verilere göre sıkça talep edilen hizmetler MiA'da yüksek yoğunluğa sahiptir. MiA ile komşu olan batıda Honsalar, Akmescit, Hisarardı, doğuda Esentepe, Kırkçeşme mahallelerinde temel hizmetlerin bile düşük yoğunlukta olması MiA'nın bu alanlara hizmet ettiğini göstermektedir. Buna karşın Kuzeykent ve Mehmet Akif Ersoy Mahalleleri MiA'ya erişimin görece sınırlı olması gerekçesiyle sıkça talep edilen hizmetler açısından daha yoğundur. Mehmet Akif Ersoy Mahallesi'nde konut altı ticaret kullanımı yaygındır. Buna karşın Kuzeykent Mahallesi'nde konuttan bağımsız ticari yapılar yer almaktadır (Şekil 2).

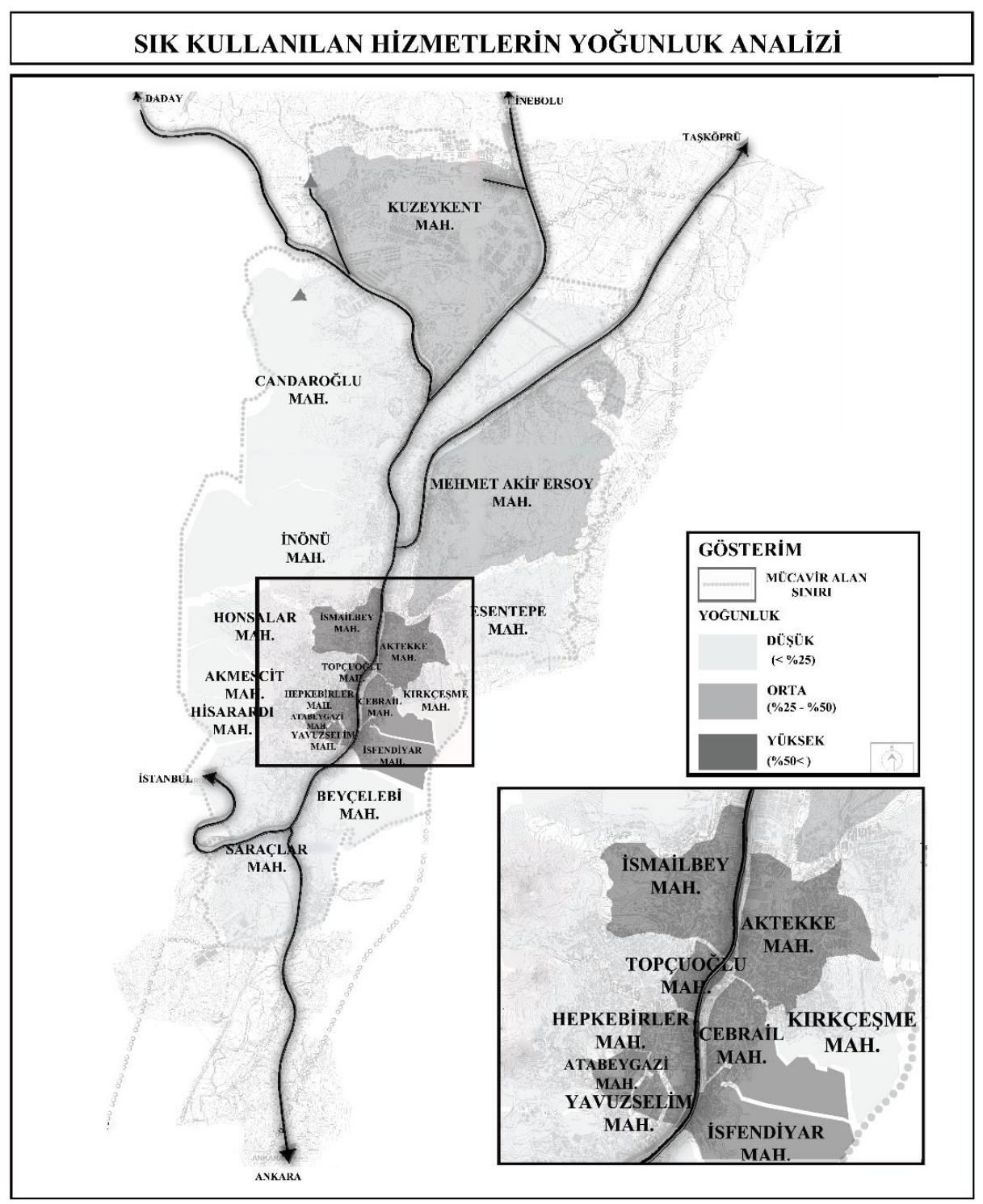

Şekil 2. Sıkça talep edilen hizmetlerin mahallelere göre yoğunlukları 
Kentte yüksek etki alanına sahip hizmetlerin kentin kuzeyinde yığılma eğiliminde olduğu görülmektedir. Kentin kuzeybatı aksı boyunca ticari birimler zemin katlarda yer almakta olup yüksek etki alanına sahip olan hizmetlerin yoğunluğu bu alanda yüksektir. Mekan gereksinimi görece fazla olan mobilya ve beyaz eşya gibi ticari işlevlerin merkezi alanlar dışında ve arazi bedeli daha düşük noktalarda yer seçmesi beklenirken MiA'da ve yeni gelişme alanlarından olan Kuzeykent mahallesinin merkezi bir noktasında yer seçtiği tespit edilmiştir.

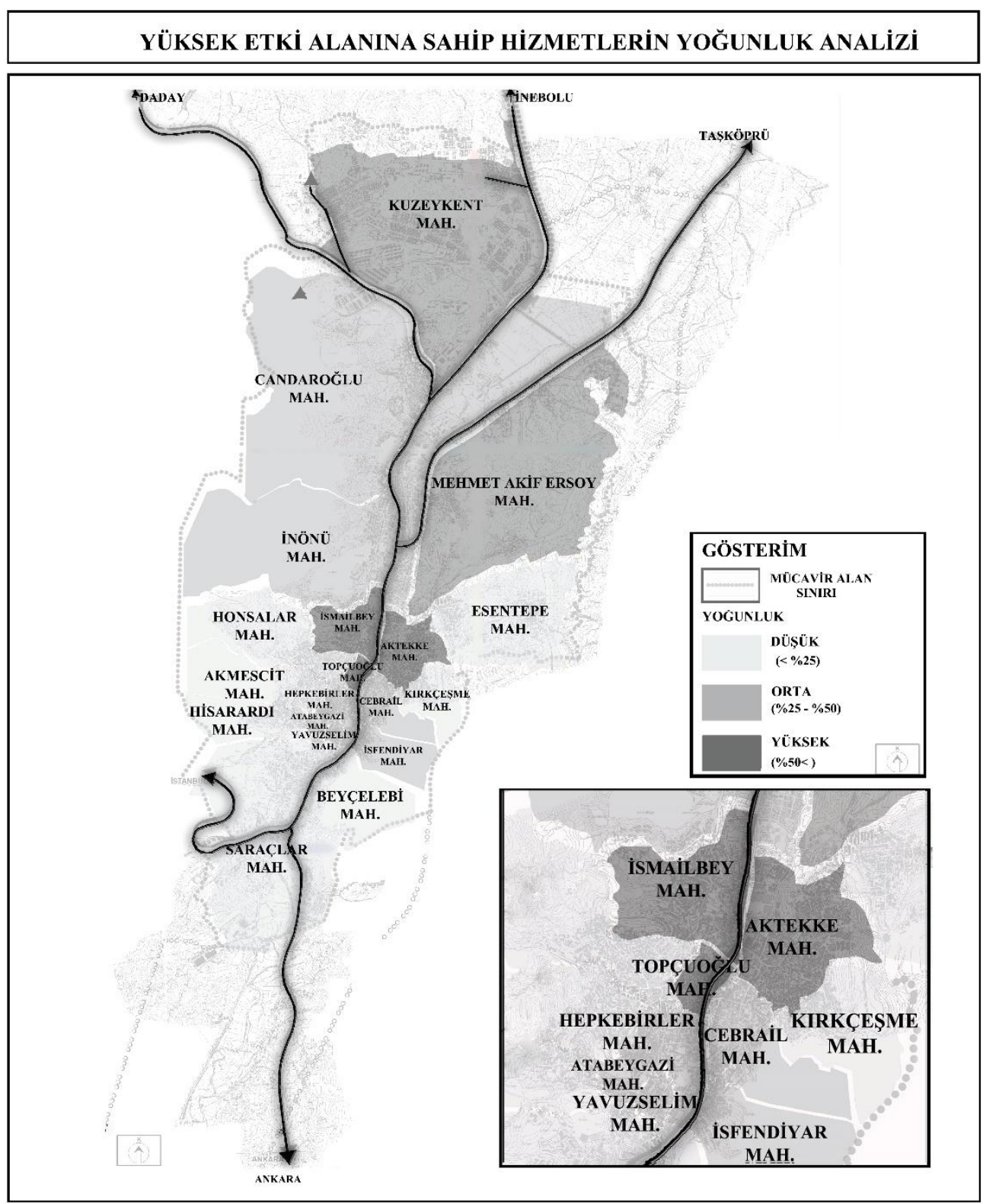

Şekil 3. Yüksek etki alanına sahip hizmetlerin mahallelere göre yoğunlukları

Kuzey aksında yer alan mahallelerde ulaşım ağına bağlantılı noktalarda otomotiv, inşaat vb. sektörlerin, konut gelişimiyle birlikte merkezi bir alanda kaldığı, güney aksında ise temel ihtiyaçlar açısından bile ticaret işlevlerinin yetersiz olduğu görülmektedir. Kuzeykent mahallesinde iş merkezi olarak çarşı niteliğindeki alanda merkezi bir konumda sıkça talep edilen hizmetler yer seçmiştir. İş merkezinin etki alanı dışındaki konut bölgelerinde temel gereksinimler, mahallenin çeperlerinde yer almaktadır. Buna karşın geniş mekân kullanımına ihtiyaç duyan ticari birimlerin merkezi noktada yer seçtiği tespit edilmiştir. 


\section{Sonuç}

Kent merkezleri günümüzde sosyal, kültürel ve ekonomik gereksinimlerin en fazla karşılandığı alanlar kabul edilmektedir. Kentsel alanda yaşayan tüm insanların ihtiyaçlarına, kaynak ve hizmetlere erişebilmeleri gerekmektedir. Özellikle günlük ihtiyaçlara kolaylıkla erişim, bir planlama ve tasarım sorunsalıdır. Jacobs (1992), kentlerin planlanmasında öncelik verilmesi gereken konunun insan ve toplum yaşamı olduğunu ifade eder. Bir kentin yaşanabilir olması için bireylerin günlük yaşamını devam ettirebileceği koşullarda olması gerekir.

Araştırmada merkezi yerler kuramından hareketle Kastamonu kent merkezinde ticaret örüntüleri, sıkça talep edilen ve yüksek etki alanına sahip hizmetler olarak sınıflandırılarak incelenmiştir. Kastamonu kentsel alanı, kent merkezinin engebeli yapısı nedeniyle kuzey yönlü olarak büyümektedir. Kentte sıkça talep edilen hizmetlerin Mï'da yığılma eğiliminde olduğu tespit edilmiştir. MïA sınırlarında yer alan mahallelerde bu hizmetlerin yoğunluğunun düşük olması MiA'nın etki alanında yer almalarından kaynaklanmaktadır. Ayrıca kentte doğu-batı yönlü olarak eğimin artması, nüfus yoğunluğunun düşmesine neden olmakta ve bu alanların erişilebilir olmasını engellemektedir.

Yüksek etki alanına sahip hizmetlerin genellikle görece geniş alan ihtiyacı olduğundan arazi bedelinin görece düşük olduğu kent çeperinde yer seçme eğiliminde olması beklenirken, gelişme alanında ana arterden daha düşük dereceli bir aksta mahallenin merkezi alanında yer seçtiği görülmüştür. Bununla birlikte MiA'yı tanımlayan mahallelerde de geniş alan ihtiyacı olan bazı hizmetlerin yer aldığı tespit edilmiştir.

20. yüzyılda Almanya'da başlayan yerleşim kuramlarından olan merkezi yerler kuramı araştırmanın çerçevesini oluşturmaktadır. Kuram, mekânda eşit olarak dağıımış statik bir coğrafi ve beşeri mekânsal yapı tanımlanmaktadır. Günümüz kentlerindeki enformasyonel ağlar, bölgelerarası eşitsizlikler ve piyasa koşullarının karmaşık yapısı, topografya gibi etkenler homojen bir mekânsal dağııımını mümkün kılmamaktadır. Bununla birlikte firma karlıı̆̆ını maksimize ederken sosyal maliyetler gibi birçok kentsel bileşeni hesaba katmamaktadır (Tekeli, 1970). Ancak tanımlanan kademeli yapı mekâna yansımakta ve mekân-hizmet alanı ilişkisiyle gerek tüketici gerekse hizmet sağlayıcı açısından avantajlar sağlamaktadır. Bu bağlamda hizmetlerin mekânsal örüntüsü ve etki alanlarının araştırılmasının, zaman, maliyet ve erişilebilirlik açısından önemli kazanımlar sunacağı, kentsel yayılmanın ve gereksiz arazi kullanımlarının önüne geçebileceği düşünülmektedir.

Araştırma alanından elde edilen bulgulara göre, bazı mahallelerde temel hizmetlerin bile yer almadığı, buna karşın bazı mahallelerin merkezi noktalarında üst kademe hizmetlerin yer aldığı görülmektedir. Bu durumun etkili olmasında kentin orta ölçekli olması ve kent içi ulaşımla tüm mahallelere erişimin rahatlıkla sağlanabiliyor olmasının etkili olduğu düşünülmektedir. Araştırma, kent ölçeğinin tüketiciler için kabul edilebilir mesafelerde etkili olduğunu ortaya koymaktadır.

\section{Teşekkür ve Bilgi Notu}

Bu araştırma Gazi Üniversitesi Şehir ve Bölge Planlama Ana Bilim Dalında yürütülen “Kentsel Merkezi İ̧ Alanı Gelişmesinin Karmaşıklık Teorisi Bağlamında Zamansal ve Mekânsal Modellenmesi" başlıkı Doktora tez çalışmasından yararlanılarak hazırlanmıştır. Makalede ulusal ve uluslararası araştırma ve yayın etiğine uyulmuştur. Çalışmada etik kurul izni gerekmemiştir.

\section{Yazar Katkısı ve Çıkar Çatışması Beyan Bilgisi}

Makalede tüm yazarlar aynı oranda katkıda bulunmuştur. Herhangi bir çıkar çatışması bulunmamaktadır.

\section{Kaynaklar}

Alderson A. ve Beckfield J. (2004). Power and position in the world city system, American Journal of Sociology 109, 811-851.

Beyhan H. C., Eren G., Aktuğ B. (2020). Perakende Market Lokasyonları için CBS Tabanlı Çok Kriterli AHP Yöntemi ile Optimal Yer Seçimi Analizi: İstanbul Örneği, Afyon Kocatepe Üniversitesi Fen ve Mühendislik Bilimleri Dergisi, 1032-1050. 
Burger M. J., Meijers E. ve Oort F. V. (2014). Regional Spatial Structure and Retail Amenities in the Netherlands, Regional Studies, 48:12, 1972-1992, DOI: 10.1080/00343404.2013.783693.

Büyükcivelek B. (2009). Reconstruction of Ankara`s Retail Geography through a Spatial Organisation Based Typological Approach, Design Principles and Practices: An International Journal-Annual Review 3 (5): 333-348. DOI:10.18848/1833-1874/CGP/v03i05/37736.

Büyükcivelek B. (2014). Empirical Analysis of the Spatial Distribution of Organised Food Retailers in Ankara with Regard to Neighbourhoods' Social, Economic and Physical Characteristics, METU Journal of the Faculty of Architecture, 31(1), June DOi: 10.4305/METU.JFA.2014.1.4.

Christaller W. (1933). Die Zentralen Orte in Süddeutschland, Wissenschaftlische Buchgesellschaft, Darmstadt, English Edition, The Central Places in Southern Germany, Prentice-Hall, Englewood, Cliffs, NJ, 1966.

Davies W. K. D. (1967). Centrality and the central place hierarchy, Urban Studies, 4, 61-79.

Erkan N. Ç. ve Yenen Z. (2009). Yerleşmelerde İmaj Analizi Konusunda Bir Yöntem: Kastamonu Örneği, Megaron, 5(2), 67-81.

lossifova, D., Doll, C.N.H. ve Gasparatos, A. (2018). Defining the Urban, Interdisciplinary and Professional Perspectives, Oxon: Routlegde 1st Edition, 245-324.

Isinkaralar K. ve Erdem R. (2021). Landscape Plants as Biomonitors for Magnesium Concentration in Some Species, International Journal of Progressive Sciences and Technologies, 29(2), 468-473.

Jacobs, J. (1992). The Death and Life of Great American Cities, Vintage Books, New York.

Karacocuk, T., Sevik, H., Isinkaralar, K. (2021). The change of $\mathrm{Cr}$ and $\mathrm{Mn}$ concentrations in selected plants in Samsun city center depending on traffic density, Landscape and Ecological Engineering, DOI: https://doi.org/10.1007/s11355-021-00483-6.

Kayacan T. and Yirmibeşoğlu F., (2017). Site Selection Criteria for Sports Retail Sector: Istanbul Case. Current Urban Studies, 5(3), 290-304.

Lösch A. (1944). Die räumliche Ordnung derWirtschaft. Gustav Fischer, Jena, 2nd edn.

Meijers E. (2007). From Central Place to Network Model: Theory and Evidence of a Paradigm Change, Tijdschrift voor Economische en Sociale Geografie, April, DOI: 10.1111/j.14679663.2007.00394.x.

Mendes, A. B. and Themido, I. H., (2004). Multi-Outlet Retail Site Location Assessment. International Transactions in Operational Research, 11(1), 1-18.

Mutlu E. ve Varol Ç. (2017). Sosyo-Ekonomik Farklılaşma ve Mekânsal Ayrışma: Bursa Metropoliten Alanı Analizi, Megaron, 12(1), 87-105.

Naryaprağı S. ve Polat E. (2020). Kent Makroformu ve Kent içi Ulaşım Etkileşimi: Isparta Örneği, Mimarlık Bilimleri ve Uygulamaları Dergisi, 5(2), DOi: https://doi.org/10.30785/mbud.565012.

Önaç A.K. ve Birişçi T. (2019). Transformation of urban landscape value perceptionover time: a Delphi technique application, EMAS, 191:741, DOI: https://doi.org/10.1007/s10661-019-7935-9.

Öztürk S. ve Özdemir Z. (2013). The effect of urban outdoor and green areas on life quality "Kastamonu model", Kastamonu University, Journal of Faculty of Forestry, 2013, 13 (1): 109116.

Öztürk S. ve Işınkaralar Ö. (2019). Kastamonu Kent Merkezinde Otopark Sorunsalı: Eleştirel Bir Değerlendirme, Uluslararası Sosyal Araştırmalar Dergisi, 12(67), 506- 511.

Öztürk S., İsmail T. S. Y. ve Işınkaralar Ö. (2020). İnanç Turizmi Odağında Benli Sultan Külliyesi Peyzaj Tasarım Önerileri. Türk Turizm Araştırmaları Dergisi, 4(1), 349-360. 
Öztürk, S., Işınkaralar, Ö., Yılmaz, D., (2021). Restorasyon çalışmaları sonrası yerel halkın algı ve tutumları (Kayseri kalesi örneği), Doğu Coğrafya Dergisi, 26(45), 183-194, DOI: https://doi.org/10.17295/ataunidcd.933070

Öztürk S., Işınkaralar Ö., Yılmaz D., Çılgınoğlu H. (2021). Bir Kültür Turizmi Destinasyonu Olarak Hasankeyf Örneğinde Ziyaretçi Memnuniyeti, Bartın Orman Fakültesi Dergisi, 23 (2), 359-369, DOI: $10.24011 /$ barofd.901027.

Ozturk, S., Isinkaralar, O., Yilmaz, D. and Cicek, E. (2021). Tourists' Perspective Of Cultural Heritage Areas: Importance-Performance Analysis of Safranbolu. Research\&Reviews In Architecture, Planning and Design, Gece Akademi, Chapter 7, pp. 133-155.

Özüduru B. H., Varol Ç. ve Ercoşkun Ö. Y. (2014). Do shopping centers abate the resilience of shopping streets? The co-existence of both shopping venues in Ankara, Turkey, Cities, 36, 145-157.

Sat N. A., Üçer Z. A. G., Varol Ç., Yenigül S. B. (2017). Sürdürülebilir Kentler için Çok Merkezli Gelişme: Ankara Metropoliten Kenti için Bir Değerlendirme, Ankara Araştırmaları Dergisi, 5(1), 98-107, Haziran.

Sat N. A. (2018). Monocentric or Polycentric? Defining Morphological Structure of of NUTS-2 regions of Turkey from 2000 to 2016, Geographica Pannonica, 22(1), 1-13, DOi: 10.5937/gp22-15726.

Savas, D. S., Sevik, H. ve Isinkaralar, K. (2021). The potential of using Cedrus atlantica as a biomonitor in the concentrations of $\mathrm{Cr}$ and $\mathrm{Mn}$, Environmental Science and Pollution Research, 28, 5544655453, DOI: https://doi.org/10.1007/s11356-021-14826-1.

Taylor P. J. (2004). World City Network: A Global Urban Analysis, Routledge 2nd Edition, London, 198250.

Tekeli, i. (1970). Yer Seçimi Teorileri, Endüstrileşme Politikası ve Organize Sanayi Bölgeleri Üstüne, Mimarlık Dergisi, 8(6), 50-55.

Wall R. S. ve Van Der Knaap G. A. (2011). Sectoral differentiation and network structure within contemporary worldwide corporate networks, Economic Geography 87, 267-308. 